\title{
Induced Interchange Heterozygosity in Sesbania aegyptiaca (Poir.) Pers.
}

\author{
S.N. Zadoo \\ Plant Improvement Division, Indian Grassland and Fodder \\ Research Institute, Jhansi 284003, India
}

Accepted September 11, 1985

Chromosomal interchanges can be effectively used to locate genes on a particular chromosome and establishing various linkage groups (Burnham 1962, 1966). They also form an important source of raising aneuploids (Khush 1973, Minocha et al. 1979). Physical mutagens have proved to be the most potent tool for induction of chromosomal aberrations including reciprocal interchanges. Irradiation induced interchanges have been reported in many species viz. Triticum (Yamashita 1951), Tradescantia (Watanabe 1962, 1973). Besides this multiple interchanges and/or those involving whole chromosomal complement have been successfully raised by recurrent irradiation, intercrossing and selection by Rana (1965) in Chrysanthemum and Brar et al. (1973), Brar and Minocha (1982) in pearl millet. Survival of interchange heterozygotes, however, depends chiefly on the mode of orientation of the multiple at metaphase plate and its subsequent disjunction, as it directly effects the viability of gametes. So an interchange heterozygote has to be accompanied by high frequency of disjunctional orientation for an adaptive advantage. The present studies are based on three interchange lines of Sesbania aegyptiaca (Zadoo 1984) with special reference to mode of orientation of interchange multiple and its consequences on fertility.

\section{Material and methods}

Dry seeds of Sesbania aegyptiaca were exposed to 10, 20, 30, 35, 40 and $45 \mathrm{Krad}$ doses of gamma-rays ( $\mathrm{Co}^{80}$ source) at Bhabha Atomic Research Centre, Trombay, India. The $\mathrm{M}_{1}$ plants raised from the treated seeds were scored for pollen stainability by dusting freshly dehisced anthers in 1: 1 Glycerol aceto-carmine solution. The slides were left overnight and stainability of pollen was recorded from 25 microscopic fields. The plants with significantly lower proportion of stainable pollen grains were subjected to meiotic studies from pollen mother cells by staining the fresh material with 1 per cent aceto-orcein.

\section{Observations}

The plant 35-1 consistently showed an association of four chromosomes and four bivalents, as against six bivalents of the control (Figs. 1-4). In 81.25 per cent cells, a ring multiple of four chromosomes was observed, whereas, chains of four chromosomes were observed in 18.75 per cent cells. Fifty per cent of chain multiples exhibited disjunctional orientation, whereas 20.07 per cent of ring multiples showed disjunctional orientation at metaphase-I (Table 1). In the plant 40-4, 70 per cent of the cells showed a multiple of four chromosomes (Fig. 5) out of which 56 per cent depicted a ring of four and 12 per cent showed a chain of four chromosomes. Rest of the cells were having a regular formation of 6 bivalents. All the chain multiples were observed to orientate non-disjunctionally. About half the ring multiples had disjunctional orientation, whereas rest of them showed non-disjunctional/discordant orientation at metaphase-I (Table 1). 
The plant 45-8 had multiples in 88 per cent cells, whereas, in 12 per cent cells a regular feature of six bivalents was observed (Figs. 6-9). An association of four chromosomes and four bivalents was observed only in 54 per cent cells, whereas, 34 per cent cells showed an association of three chromosomes, four bivalents and a univalent (Table 1).

The chiasma frequency per cell varied from 9 to 13 in $35-1$ and $40-4$, and 7 to 13 in 45-8, as compared to 8 to 12 of the homozygote. The corresponding averages being $11.06,10.6$ and 10.2 in $35-1,40-4$ and $45-8$, respectively as compared to 10.18 of the homozygote. The terminalization coefficient works out to be $0.81,0.78$ and 0.85 in $35-1,40-4$ and $45-8$, respectively as compared to 0.78 of the homozygote (Table 2). In 56.66 per cent cells of $35-1$ one of the chi-

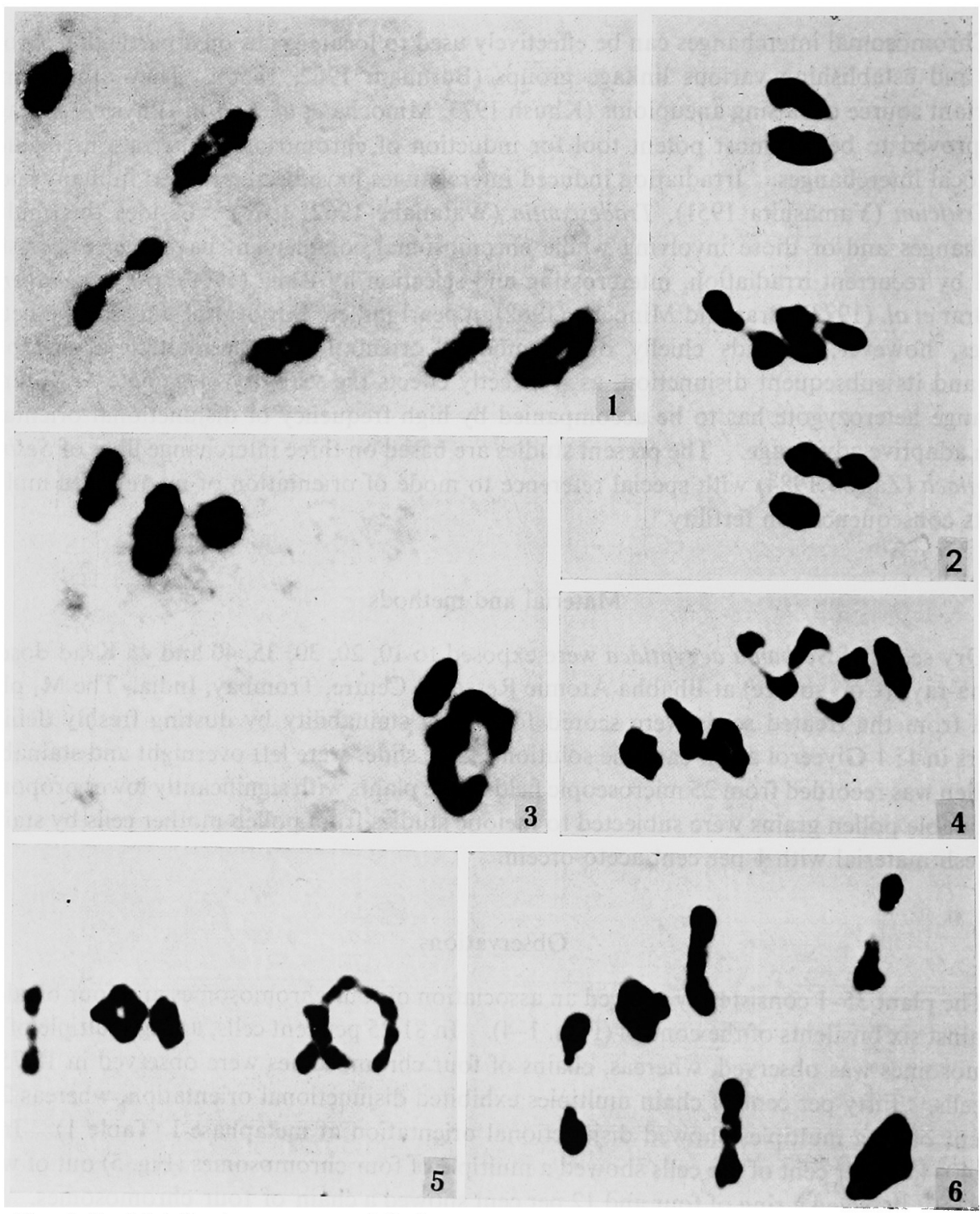

Figs. 1-6. Meiotic chromosomes of Sesbania aegyptiaca. 1, metaphase-I of control 6II. 2-4, Interchange multiples of 35-1. 2, disjunctional chain of 4 chromosomes. 3, non-disjunctional ring of 4 chromosomes, 4 , disjunctional ring of 4 chromosomes. 5, non-disjunctional ring of four and four bivalents in 40-4. 6-10, chromosomal associations in 45-8. 6, normal 6 II. 
Table 1. Frequency and orientation of interchange multiple at Metaphase-I

\begin{tabular}{|c|c|c|c|c|c|c|}
\hline \multirow{2}{*}{ Association } & \multirow{2}{*}{$\begin{array}{l}\text { No. of } \\
\text { cells }\end{array}$} & \multicolumn{3}{|c|}{ Orientation of multiple } & \multicolumn{2}{|c|}{ Expected percentage } \\
\hline & & Disjunctional & $\begin{array}{l}\text { Non-disjun- } \\
\text { ctional }\end{array}$ & Discordant & $\begin{array}{l}\text { Balanced } \\
\text { gametes }\end{array}$ & $\begin{array}{l}\text { Unbalanced } \\
\text { gametes }\end{array}$ \\
\hline \multicolumn{7}{|l|}{$45-1$} \\
\hline $\mathbf{R}_{4}+4 \mathrm{II}$ & 52 & 12 & 23 & 17 & 18.75 & 65.21 \\
\hline $\mathrm{C}_{4}+4 \mathrm{II}$ & 12 & 6 & 6 & - & 9.37 & 9.37 \\
\hline Total & 64 & 18 & 29 & 17 & 28.12 & 71.88 \\
\hline \multicolumn{7}{|l|}{$40-4$} \\
\hline $6 \mathrm{II}$ & 15 & 15 & - & - & 15.00 & 15.00 \\
\hline $\mathbf{R}_{4}+4 \mathrm{II}$ & 29 & 15 & 7 & 7 & 30.00 & 28.00 \\
\hline $\mathrm{C}_{4}+4 \mathrm{II}$ & 6 & - & 6 & - & - & 12.00 \\
\hline Total & 50 & 30 & 13 & 7 & 45.00 & 55.00 \\
\hline \multicolumn{7}{|l|}{$45-8$} \\
\hline 6II & 6 & 6 & - & - & 12.00 & - \\
\hline $\mathrm{C}_{4}+4 \mathrm{II}$ & 11 & 2 & 9 & - & 4.00 & 18.00 \\
\hline $\mathrm{A}_{4}+4 \mathrm{II}$ & 16 & - & - & - & - & - \\
\hline $\mathrm{C}_{3}+4 \mathrm{II}+1 \mathrm{I}$ & 5 & - & - & - & - & - \\
\hline $\mathrm{A}_{3}+4 \mathrm{II}+1 \mathrm{I}$ & 12 & - & - & - & 一 & - \\
\hline Total & 50 & - & - & - & - & - \\
\hline
\end{tabular}

Table 2. Chiasma frequency of homozygote and translocation heterozygotes

\begin{tabular}{ccccccc}
\hline \hline \multirow{2}{*}{ Taxon } & \multicolumn{2}{c}{$\begin{array}{c}\text { Number of chiasma } \\
\text { per cell }\end{array}$} & & \multicolumn{2}{c}{$\begin{array}{c}\text { Number of terminalized } \\
\text { chiasma per cell }\end{array}$} & \multirow{2}{*}{$\begin{array}{c}\text { Termina- } \\
\text { lization } \\
\text { coefficient }\end{array}$} \\
\cline { 2 - 3 } & Range & Mean & & Range & Mean & \\
\cline { 1 - 1 } Homozygote & & & & & & \\
(Control) & $8-11$ & 10.18 & & $8-10$ & 7.96 & 0.781 \\
$35-1$ & $9-13$ & 11.06 & & $6-11$ & 9.06 & 0.819 \\
$40-4$ & $7-13$ & 10.6 & & $5-11$ & 8.32 & 0.784 \\
$45-8$ & $7-13$ & 10.2 & & $6-11$ & 8.76 & 0.858 \\
\hline
\end{tabular}
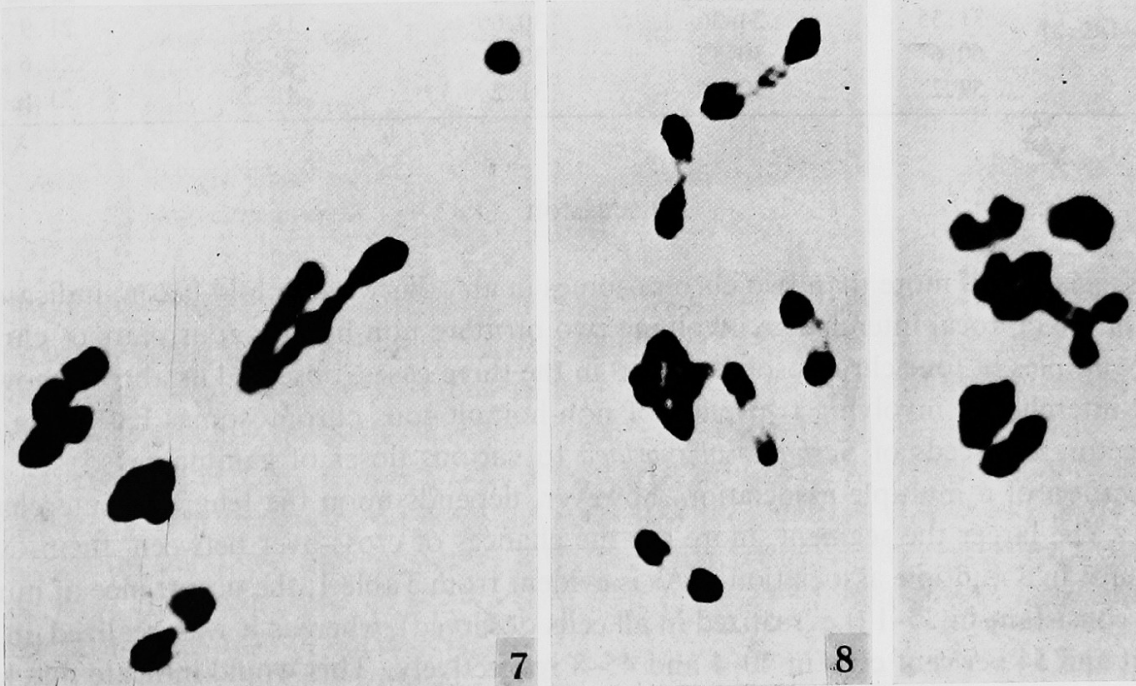

Figs. 7-9. Chromosomal associations in $45-8$, cont. $7,1 \mathrm{III}+4 \mathrm{II}+1 \mathrm{II} .8$ and $9, \mathrm{~A}_{4}+4 \mathrm{II}$, resulting from chiasma formation in interstitial segments. 
asmata in the interchange multiple was found to be unterminalized at metaphase-I. The chiasmata in the interchange multiple of $40-4$ were mostly terminalized by metaphase-I except in 14.28 per cent multiples only. The nature of metaphase-I association in $45-8$, indicated that in most of the multiples the chiasmata were found in interstitial segments (Figs. 8-9).

At anaphase-I, 14 per cent cells in 35-1 show unequal disjunction of 7:5 followed by regular anaphase-II, no chromosomes or parts thereof were found to be lagging at anaphase-I and II. In 40-4, 84 per cent of anaphase-I cells exhibited a normal numerical disjunction of 6:6 while 16 per cent cells had a disjunction of $7: 5$ chromosomes. The percentage of normal disjunction (6: 6) was however, lowest in 45-8, where it was observed in 66 per cent cells, 20 per cent cells showed an unequal disjunction of $7: 5$ chromosome, while lagging chromosomes were observed in 14 per cent cells (Table 3 ). The pollen stainability percentage was found to be $31.35,60.6$ and 59.2 in $35-1,40-4$ and $45-8$, respectively as compared to 97.12 per cent in the homozygote. The range of pollen grain size was found to be higher in $35-1$ and $45-8$ and lower in $40-4$ as compared to that of homozygote (Table 4).

Table 3. Anaphase I disjunction of interchange heterozygotes

(Figures within brackets indicate \%)

\begin{tabular}{ccccc}
\hline Taxon & $\begin{array}{c}\text { Number of } \\
\text { cells }\end{array}$ & $\begin{array}{c}\text { Normal } \\
6: 6 \\
\text { disjunction }\end{array}$ & $\begin{array}{c}\text { Abnormal } \\
7: 5 \\
\text { disjunction }\end{array}$ & $\begin{array}{c}\text { With lagging } \\
\text { chromosomes }\end{array}$ \\
\hline $35-1$ & 50 & $43(86)$ & $7(14)$ & - \\
$40-4$ & 50 & $42(84)$ & $8(16)$ & - \\
$45-8$ & 50 & $33(66)$ & $10(20)$ & $7(14)$ \\
\hline
\end{tabular}

Table 4. Pollen stainability and size in translocation heterozygotes and normal plants

\begin{tabular}{ccccccc}
\hline \hline \multirow{2}{*}{ Taxon } & \multirow{2}{*}{$\begin{array}{c}\text { Pollen } \\
\text { stainability } \\
\%\end{array}$} & \multicolumn{3}{c}{ Stainable } & & \multicolumn{2}{c}{ Unstainable } \\
\cline { 3 - 4 } \cline { 6 - 7 } & & Range & Mean & & Range & Mean \\
\cline { 3 - 6 } & & $27-33$ & 29.76 & & $18-24$ & 21.22 \\
Control & 97.12 & $24-36$ & 30.66 & & $18-27$ & 21.9 \\
$35-1$ & 31.35 & $30-33$ & 30.6 & & $21-24$ & 21.6 \\
$40-4$ & 60.6 & $30-36$ & 31.2 & & $18-24$ & 21.6 \\
$45-8$ & 59.2 & & &
\end{tabular}

\section{Discussion}

An association of more than two chromosomes in an otherwise diploid taxon, indicates the existence of a reciprocal interchange involving two or more non-homologous pairs of chromosomes. Multiples of four chromosomes found in the three cases, observed as above, show that reciprocal interchange involving two pairs of non-homologous chromosomes has taken place after subjecting the seeds of Sesbania aegyptiaca to various doses of gamma rays.

Realization of a multiple association, however, depends upon the length of interchanged segments. The larger the segment, more are the chances of cross-over between them, which in turn results in a multiple association. As is evident from Table 1, the occurrence of multiple of four is consistant in 35-1 (i.e. realized in all cells observed), whereas it was realized in only 70 per cent and 54 per cent cells in $40-4$ and $45-8$ respectively. This would indicate that length of interchanged segments is largest in 35-1, followed by 40-4 and 45-8. In the latter two cases there is an occasional failure of crossing over between all the four pairing segments which in turn 
results into formation of trivalents, bivalents and univalents. Furthermore, the absence of ring multiples in $45-8$ also suggests that interchanged segment is very small in this case. The small interchange segment in turn results into a large interstitial segment. The presence of the large interstitial segments leads to formation of associations having chiasmata in interstitial segments.

The fertility and eventual survival of an interchange depends chiefly on the mode of orientation of the multiple at metaphase plate. Symmetrical shape of chromosomes together with terminalized chiasmata, increase the probability of disjunctional orientation, because rings with equal intercentromeric distance and terminal chiasmata tend to be more pliable and can easily arrange disjunctionally (Burnham 1956, Darlington 1965). Furthermore alternate/disjunctional orientation in ring multiples is greater if centromeres are effectively equidistant, so that each centromere is in equal communication with those adjacent to it and becomes co-orientated relative to both of them. The effective distance depends not only on morphology of chromosomes, but also on position of chiasmata at metaphase-I (Lewis and John 1963).

It appears that disjunctional orientation necessitates a greater flexibility of multiple. Keeping this in view, chain multiples should orientate in this manner more often than rings. This presumption holds good in 35-1, where 50 per cent of chain multiples observed orientate disjunctionally as compared to 18.75 per cent of rings with disjunctional orientation (Table 1), while it does not hold good in case of 40-4, where 51.7 per cent of ring multiples orientated disjunctionally and all chain multiples showed non-disjunctional orientation.

Table 5. Relationship between chiasma terminalization and orientation of multiple at metaphase I

\begin{tabular}{|c|c|c|c|}
\hline \multicolumn{2}{|c|}{$\begin{array}{l}\text { Nature of multiple and } \\
\text { orientation }\end{array}$} & \multirow[t]{2}{*}{$\begin{array}{l}\% \text { of multiples with } \\
\text { all terminalized } \\
\text { chiasma }\end{array}$} & \multirow[t]{2}{*}{$\begin{array}{c}\% \text { of multiples } \\
\text { with one unter- } \\
\text { minalized chiasma }\end{array}$} \\
\hline \multicolumn{2}{|l|}{$35-1$} & & \\
\hline \multirow[t]{2}{*}{ Rings } & Disjunctional & 66.66 & 33.33 \\
\hline & Non-disjunctional & 8.33 & 91.66 \\
\hline \multirow[t]{2}{*}{ Chains } & Disjunctional & 66.66 & 33.33 \\
\hline & Non-disjunctional & 33.33 & 66.66 \\
\hline \multicolumn{4}{|l|}{$40-4$} \\
\hline \multirow[t]{2}{*}{ Rings } & Disjunctional & 86.66 & 13.33 \\
\hline & Non-disjunctional & 85.71 & 14.28 \\
\hline \multirow[t]{2}{*}{ Chains } & Disjunctional & - & - \\
\hline & Non-disjunctional & 83.33 & 16.66 \\
\hline \multicolumn{4}{|l|}{$45-8$} \\
\hline \multirow[t]{2}{*}{ Chains } & Disjunctional & 44.44 & 55.55 \\
\hline & Non-disjunctional & 50.00 & 50.00 \\
\hline
\end{tabular}

The observations on terminalization of chiasmata in the interchange multiples at metaphaseI may have some relationship with their orientation (Table 5). As is evident, the complete terminalization in multiple of 35-1 had some bearing on its orientation due to change in effective intercentromeric distance brought about by terminalized/non-terminalized chiasmata. However, this assumption does not hold true again, in case of interchange multiples of 40-4 where 86.6 per cent disjunctional ring multiples had terminalized chiasmata, while 85.71 per cent of non-disjunctional ring multiples also had fully terminalized chiasmata. Similar was the case with chain multiples of 40-4 where 83.3 per cent of non-disjunctional chains had complete terminalization of chiasmata.

As is apparent from the foregoing account, the orientation of multiple, which is of primary importance for fertility/survival of an interchange complex, can hardly be explained on physical characteristics of chromosomes and position of chiasmata alone. The mode of oritentation 
has been reported to be under genetic control (Thompson 1956; Lawrence 1958 and Rees 1961).

Besides the above factors the fertility can also be effected by discordant orientation of ring multivalents on the metaphase plate i.e. two centromeres on opposite sides of a ring are directed to different spindle poles, and the two intervening centromeres are not co-oriented. This type of orientation may lead to numerical and/or genetically unbalanced gametes depending on the fact whether the ring disjoins to give unequal $(3: 1)$ or equal $(2: 2)$ segregation. Percentage of such rings being 26.58 in 35-1, which in turn accounts for 14 per cent cells with unequal disjunction (7:5) at anaphase-I (Table 3). It implies that roughly about 50 per cent of discordant rings disjoin to give 3: 1 segregation and others disjoin to give numerically equal (2: 2) segregation. In 40-4, 14 per cent of cells show discordant rings, whereas 12 per cent of cells show unequal disjunction of 7:5 at anaphase-I (Table 3). In either case, however, the resultant gametes are bound to be unviable, carrying as they are deficient/duplicate combinations.

The chiasma frequency in all the interchange heterozygotes was found to be higher as compared to homozygotes (Table 2), which could be due to delayed terminalization/non terminalization of chiasmata and/or increase in crossing over following mutagenic treatment (Lawrence 1961). In the present heterozygotes, however, latter appears to be the case, as coefficient of terminalization was found to be either equal or more than that of homozygote (Table 2).

If pollen stainability is taken as an index for viability of gametes it is evident that viability is $31.35,60.6$ and 59.2 per cent in $35-1,40-4$ and $45-8$ respectively as compared to 97.12 per cent of the homozygote (Table 4). This is closely corroborated by the expected percentage of viable gametes (Table 1).

Pollen grain size of translocation heterozygotes showed a higher range of variability as compared to homozygotes. This could be accounted on the assumption that at meta-anaphase-I, most of cells in heterozygotes show a non-disjunctional orientation resulting into duplication/ deficiencies, that is turn manifest in terms of variability in size and stainability of pollen grains.

It is expected that studies on the progenies of these interchange heterozygotes in Sesbania aegyptiaca would result in establishment of hetero and homozygous translocation stocks which could be further utilized in genetic analysis.

\section{Summary}

Three plants with reciprocal translocation of chromosomes were isolated from $\mathrm{M}_{1}$ progeny of Sesbania aegyptiaca (Poir.) Pers., after treating the dry seeds with 10, 20, 30, 40 and 45 Krad doses of gamma rays. The cytological observation of these plants revealed that in each case a reciprocal interchange involving two non-homologous chromosomes has taken place. The plants have been studied for their meiotic behaviour, with particular reference to type and frequency of multiple associations, mode of orientation of interchange multiple at metaphase-I, disjunction at anaphase-I, and chiasma frequency. The consequences of these factors vis- $a$ $v i s$ the fertility has been discussed.

\section{Acknowledgements}

Sincere thanks are due to Director, I.G.F.R.I. for facilities during the course of this study and to Dr. S. K. Gupta for suggestions. 


\section{References}

Brar, D. S. and Minocha, J. L. 1982. Multiple chromosomal interchanges in Pearl Millet. Theor. Appl. Genet. 61: $105-108$.

-, Minocha, J. L. and Gill, B. S. 1973. Translocation in Pennisetum typhoides involving all chromosomes in one complex. Curr. Sci. 42: 653-654.

Burnham, C. R. 1956. Chromosomal interchanges in plants. Bot. Rev, 22: 419-552.

- 1962. Discussions in Cytogenetics. Minneapolis. Minn. Burgess.

- 1966. Cytogenetics in Plant Improvement, In "Plant Breeding". Ed. K. J. Frey. IOWA State University Press, IOWA.

Darlington, C. D. 1965. Cytology. J \& A Churchill Ltd. London.

Khush, G. S. 1973. Cytogenetics of Aneuploids. New York. London. Acad. Press.

Lawrence, C. W. 1958. Genotypic control of chromosome behaviour in rye VI. Selection for disjunction frequency. Heredity 12: 127-131.

- 1961. The effect of irradiation on chiasma formation in Tradescantia. Radiation Botany 1: 92-96.

Lewis, K. R. and John, B. 1963. Chromosome Marker. Boston, Little Brown.

Minocha, J. L., Saini, R. S. and Brar, D. S. 1979. Aneuploids from chromosomal interchanges in Pearl millet. Can. J. Genet. Cytol. 21: 571.

Rana, R. S. 1965. Induced interchange heterozygosity in diploid chrysanthemum. Chromosoma 16: 477-485.

Rees, H. 1961. Genotypic control of chromosome form and behaviour. Bot. Rev, 27: 288-318.

Thompson, J. B. 1956. Genotypic control of chromosome behavior in rye II. Disjunction in meiosis in interchange heterozygotes. Heredity 10: 99-108.

Watanabe, H. 1962. A X-ray induced strain of ring of 12 in Tradescantia paludosa. Nature (Lond.) 193: 603.

-1973 . Cytogenetic studies on reciprocal translocations induced by X-rays in Tradescantia paludosa. Heredity $31: 85-94$.

Yamashita, K. 1951. Studies on X-ray induced reciprocal translocations in einkorn wheats III. A newly synthesized ring of 14 chromosomes in a complex heterozygote, aegilopoides-monococcum. Cytologia 16: 164-176.

Zadoo, S. N. 1984. Chromosomal interchange stocks in Sesbania aegyptiaca (Poir.) Pers. Curr. Sci. 53: 993-994. 